\title{
Estudo da presença da toxina microcistina na água de reservatório de Mundaú (Garanhuns-PE) pelas metodologias ELISA e CLAE
}

\author{
Study on the occurrence of microcystin toxin in water reservoir of \\ Mundaú (Garanhuns-PE) by ELISA and HPLC methodologies
}

RIALA6/1602

Catarina Paula da Silva RAMOS ${ }^{1,2}$, Irapuan Oliveira PINHEIRO ${ }^{3}$, Edvani Maria da SILVA ${ }^{1}$, Kátia Christina LEANDRO

*Endereço para correspondência: ${ }^{1}$ Laboratório de Cianobactérias, Coordenação de Diagnóstico Laboratorial em Vigilância
Ambiental e Toxicologia, Gerência de Diagnóstico Laboratorial em Vigilância Sanitária e Ambiental, Laboratório Central
de Saúde Pública (LACEN-PE), Rua Fernandes Vieira, s/n, Boa Vista, CEP 50050-210, Recife, PE/Brasil. Tel: (81) 31816560
E-mail: catarinasramos@yahoo.com.br
${ }^{2}$ Rede Nordeste de Biotecnologia (RENORBIO), Universidade Federal Rural de Pernambuco - UFRPE
${ }^{3}$ Laboratório de Processos e Produtos Biotecnológicos (LPPB), Instituto de Ciências Biológicas, Universidade de Pernambuco - UPE
${ }^{4}$ Laboratório de Eletroanalítica, Departamento de Química, Instituto Nacional de Controle de Qualidade em Saúde, Fundação
Oswaldo Cruz
Recebido: 02.09.2013 - Aceito para publicação: 19.06.2014

RESUMO

As cianobactérias são responsáveis pela produção de cianotoxinas que, uma vez acumuladas, podem causar sérios danos à saúde humana e animal. As microcistinas são o tipo mais comum de cianotoxinas e são promotoras de tumores hepáticos. O reservatório de Mundaú, localizado no município de Garanhuns-PE, foi o local escolhido por apresentar histórico de florações de cianobactérias produtoras de microcistinas. Neste trabalho foi investigada a presença de microcistinas em amostras de água bruta do reservatório do rio Mundaú utilizando-se as técnicas de Enzyme Linked Immunosorbent Assay (ELISA) e Cromatografia Líquida de Alta Eficiência (CLAE). Durante quinze meses consecutivos, as amostras de água foram coletadas em duplicata no ponto de captação deste manancial e analisadas por ambas metodologias ELISA e CLAE. A presença de microcistinas foi detectada em $100 \%$ das amostras, confirmando-se a relevância do monitoramento de microcistinas em águas de abastecimento público, pois assim como o rio Mundaú, vários mananciais de Pernambuco apresentam florações de cianobactérias que podem ser tóxicas. Este trabalho deixou como legado a implantação da referida análise no Laboratório Central de Saúde Pública (LACEN-PE), e demonstrou sua importância como metodologia complementar à contagem das cianobactérias, para fornecer subsídios às ações preventivas de vigilância à saúde.

Palavras-chave. microcistinas, ELISA, CLAE, cianotoxinas, água.

\section{ABSTRACT}

Cyanobacteria are responsible for the production of cyanotoxins, and once accumulated, it might cause serious harm to the human and animals health. Microcystins are the most common type of cyanotoxins and they cause liver tumor. The Mundaú reservoir, located in the municipality of Garanhuns-PE, was the selected site for presenting historical blooms of microcystins-producing cyanobacteria. This study analyzed the occurrence of microcystins in raw water samples from the Mundaú reservoir by using Enzyme Linked Immunosorbent Assay (ELISA) and High Performance Liquid Chromatography (HPLC) methodologies. During the consecutive fifteen months, water samples were collected in duplicate at the intake point of this water source, and they were analyzed by both ELISA and HPLC techniques. The presence of microcystins was detected in $100 \%$ of analyzed samples, confirming the relevance of performing the microcystins monitoring in public water supplies. And as well as the Mundaú river, various water sources of Pernambuco show cyanobacterial blooms, which might be toxic. The techniques used in this study were implemented in the Central Laboratory of Public Health of Pernambuco (LACEN-PE), and they showed to be a relevant tools as a complementary methodology to the cyanobacteria counting assay for providing preventive subsidies to the health surveillance.

Keywords microcystin, ELISA, HPLC, cyanotoxins, water. 


\section{INTRODUÇÃO}

A contaminação das águas naturais representa um dos principais riscos à saúde pública, sendo amplamente conhecida a estreita relação entre a qualidade da água e as enfermidades que acometem as populações, especialmente aquelas não atendidas por serviços de saneamento. No Brasil, as péssimas condições sanitárias resultam na degradação generalizada dos elementos naturais e, certamente, dos recursos hídricos ${ }^{1}$.

Como consequência, ocorre a eutrofização dos mananciais, tornando-os propícios à proliferação excessiva de algas, comprometendo a qualidade da água e restringindo a sua utilização para abastecimento público ${ }^{2,3}$.

O crescimento excessivo de algas em reservatórios brasileiros é uma realidade e tem prejudicado o uso da água para diversas finalidades. Alguns grupos de algas, em especial as do grupo das cianofíceas ou cianobactérias, podem causar gosto e odor desagradáveis na água. Porém, o maior problema está no fato de que podem produzir toxinas, tais como as microcistinas, que causam a morte de animais, domésticos e selvagens, e também intoxicação humana ${ }^{4-6}$.

Devido à morte ou lise celular das cianobactérias, ocorre a liberação das cianotoxinas, que podem causar problemas de saúde nos seres humanos, como lesões no fígado(hepatotoxinas), no sistemanervoso(neurotoxinas) ou, apenas, irritação na pele (dermatotoxinas) $)^{7-9}$.

O tipo mais comum de intoxicação envolvendo cianobactérias é ocasionado por hepatotoxinas, que apresentam uma ação mais lenta podendo causar morte num intervalo de poucas horas a poucos dias. As espécies já identificadas como produtoras dessas toxinas estão incluídas nos gêneros Microcystis, Anabaena, Nodularia, Oscillatoria, Nostoc e Cylindrospermopsis ${ }^{10}$.

Há evidências de que populações abastecidas por reservatórios que apresentam extensas florações podem estar expostas a baixos níveis de toxinas por longo período. Essa exposição prolongada deve ser considerada como um sério risco à saúde uma vez que as microcistinas são o tipo mais comum de hepatotoxinas de cianobactérias, sendo potentes promotoras de tumores ${ }^{11}$ e, portanto, este consumo continuado de pequenas doses pode levar a uma maior incidência de câncer hepático na população exposta. Como consequência, é importante que os efeitos crônicos de exposições prolongadas por ingestão oral de baixas concentrações de cianotoxinas sejam avaliados tanto do ponto de vista epidemiológico como toxicológico.

Um estudo recente mostrou que as microcistinas apesar de serem comumente caracterizadas como hepatotoxinas, mostram uma neurotoxicidade potencial, mas os efeitos neurotóxicos do seu mecanismo não estão claros $^{12}$.

A Portaria $n^{\circ} 2914 / 2011^{13}$, do Ministério da Saúde, estabelece os procedimentos e responsabilidades relativos ao controle e vigilância da qualidade da água para consumo humano e seu padrão de potabilidade, sendo que dentre outras análises, determina que a pesquisa e microcistinas na água seja obrigatória e tenha acompanhamento semanal sempre que a densidade de cianobactérias estiver acima de 20.000 cel. $\mathrm{mL}^{-1}$.

Segundo Chorus e Bartram ${ }^{14}$, a Organização Mundial de Saúde, no sentido de proteger a saúde pública, estabeleceu como limite máximo aceitável para microcistina na água destinada ao consumo humano o valor de $1 \mu \mathrm{g} . \mathrm{L}^{-1}$. O Brasil foi o primeiro país a criar uma legislação específica, a qual estabeleceu o valor máximo de microcistinas permitido na água de abastecimento público em $1 \mu \mathrm{g} . \mathrm{L}^{-1}$, porém para águas de abastecimento de hospitais que realizam hemodiálise, esse valor tem que ser igual à zero ${ }^{15}$.

No Brasil, 32 espécies de cianobactérias tóxicas já foram descritas para regiões tropicais e subtropicais do país e estão distribuídas nas seguintes ordens: 12 Chroococcales, 10 Oscillatoriales e 10 Nostocales. A região tropical do Brasil apresenta menos biodiversidade de cianobactérias tóxicas (14 espécies) do que a parte subtropical do país (27 espécies). Microcystis (7 espécies) e Anabaena (6 espécies) são os gêneros com maior número de espécies tóxicas ${ }^{16}$.

Pesquisas da comunidade fitoplanctônica em mananciais no estado de Pernambuco demonstraram intensa proliferação de cianobactérias, apresentando em alguns meses densidade média acima de $10^{6} \mathrm{cel}$. $\mathrm{mL}^{-1}$, constituindo indicativo de potencial tóxico com relação à presença de cianotoxinas. Entretanto, estudos desta natureza no estado, até o momento, são escassos. A presença de cianotoxinas também foi observada em florações de Anabaena spiroides Klebahn, Pseudanabaena sp., Cylindrospermopsis raciborskii (Woloszynska) Seenaya \& Subba Raju e Microcystis aeruginosa (Kützing) Kützing ocorridos em importantes reservatórios do estado $^{17}$.

Foi também em Pernambuco, na cidade de Caruaru em 1996, o primeiro caso confirmado de 
mortes humanas causadas por cianotoxinas, quando 130 pacientes renais crônicos, após terem sido submetidos a sessões de hemodiálise passaram a apresentar um quadro clínico compatível com uma grave hepatotoxicose. Desses, 60 pacientes vieram a falecer até 10 meses após o início dos sintomas. As análises confirmaram a presença de microcistinas e cilindrospermopsina no carvão ativado utilizado no sistema de purificação de água da clínica, e de microcistinas em amostras de sangue e fígado dos pacientes intoxicados ${ }^{18,19}$. Além disso, as contagens das amostras do fitoplâncton do reservatório que abastecia a cidade demonstraram uma dominância de gêneros de cianobactérias comumente relacionados com a produção de microcistinas.

A literatura também apresenta registros de intoxicação de peixes obtidos em ambientes eutrofizados com presença de cianotoxinas, chegando em alguns casos a ser evidenciada mortalidade de toneladas desses animais em decorrência do processo denominado bioacumulação ${ }^{20}$. Portanto, torna-se necessário $\mathrm{o}$ monitoramento de microcistinas em água destinada a população e ao uso em serviços de saúde pública, para evitar todos os riscos adversos à saúde humana.

Os principais objetivos deste trabalho foram verificar a presença de microcistinas em amostras de água do reservatório de Mundaú, localizado no município de Garanhuns-PE, utilizando os métodos de detecção ELISA e Cromatografia Líquida de Alta Eficiência (CLAE) e também implementar estas técnicas de detecção e quantificação no Laboratório Central de Saúde Pública de Pernambuco Dr. Milton Bezerra Sobral (LACEN-PE), a fim de criar dados para subsidiar ações de vigilância ambiental, epidemiológica e sanitária no estado de Pernambuco.

\section{MATERIAL E MÉTODOS}

\section{Área de estudo}

O reservatório do Mundaú (latitude $8^{\circ} 56^{\prime} 42,8^{\prime \prime} \mathrm{S}$ e longitude $36^{\circ} 29^{\prime} 27,4^{\prime \prime} \mathrm{W}$ ) localiza-se a $232 \mathrm{~km}$ do Recife-PE, no município de Garanhuns. Faz parte da Bacia hidrográfica do Rio Mundaú, que apresenta nascente em Garanhuns e foz na Lagoa do Mundaú, Maceió-AL, com extensão de 4.090,39 km², a qual atinge 15 municípios no estado de Pernambuco, além de outros municípios no estado de Alagoas $^{21}$. O reservatório apresenta capacidade de acumulação de água de aproximadamente $1.968 .600 \mathrm{~m}^{3}$ e é considerado um importante sistema de abastecimento, pois fornece água para o município de Garanhuns na Região Agreste recebendo grande carga poluidora de esgotos domésticos e industriais da região ${ }^{22} \mathrm{e}$, frequentemente, apresenta florações de cianobactérias.

\section{Procedimento de coleta}

Amostras de água de $500 \mathrm{~mL}$ foram coletadas pelos técnicos da Agência Pernambucana de Vigilância Sanitária (APEVISA), no ponto de captação do reservatório de Mundaú-PE, antes do envio para a estação de tratamento. Após a coleta, as amostras foram colocadas em frascos de polietileno denso, acondicionadas a $4{ }^{\circ} \mathrm{C}$ e transportadas ao abrigo da luz. Foram adicionados $2 \mathrm{~mL}$ de ácido clorídrico p.a às amostras destinadas a pesquisa de microcistina visando à conservação das mesmas. Antes da adição do conservante, alíquotas de $3 \mathrm{~mL}$ de cada uma das amostras foram coradas com lugol $1 \%$ e sedimentadas em cubetas de Utermöhl ${ }^{23}$ de $3 \mathrm{~mL}$ por um período de 24 horas para a contagem de cianobactérias.

Foram analisadas 15 amostras de água em duplicata coletadas mensalmente, no período de janeiro de 2011 a abril de 2012, no Laboratório Central de Saúde Pública de Pernambuco Dr. Milton Bezerra Sobral (LACEN-PE).

\section{Análise de microcistinas}

Os métodos de análise utilizados foram o de imunoensaio enzimático - ELISA (Enzyme Linked Immunosorbent Assay) e o cromatográfico - CLAE (Cromatografia Líquida de Alta Eficiência).

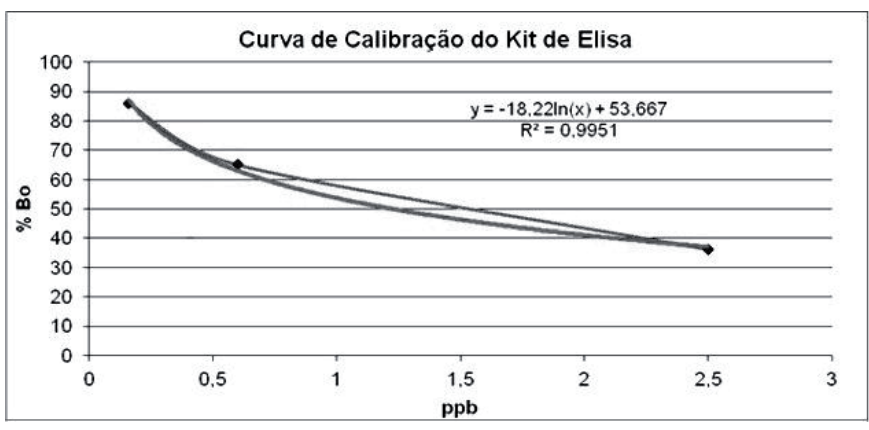

Figura 1. Curva analítica obtida para o kit de Elisa utilizado na quantificação de microcistinas

Fonte: Elaborado pelo autor 


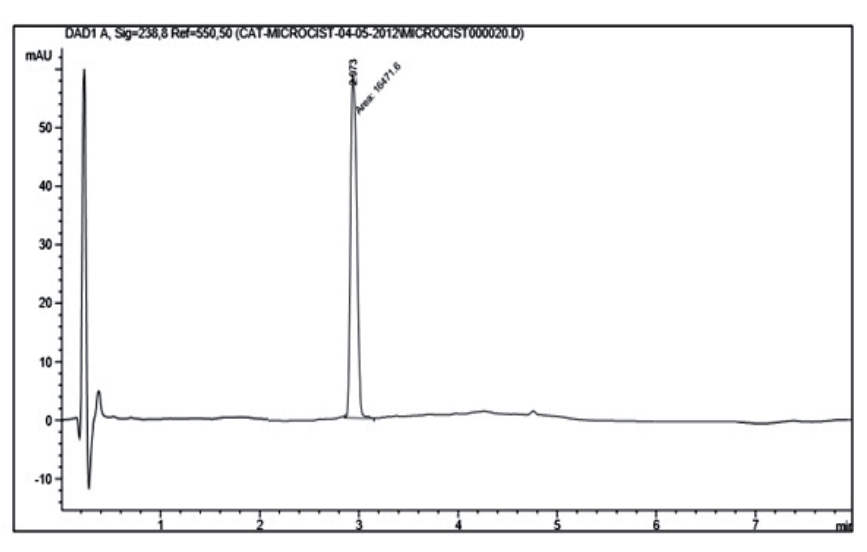

Figura 2. Cromatograma representativo do padrão de microcistina-LR no CLAE

Fonte: Elaborado pelo autor

\section{Preparo das amostras para o ELISA}

De cada uma das 15 amostras coletadas no reservatório de Mundaú foram retiradas alíquotas de $15 \mathrm{~mL}$, após homogeneização, e colocadas em vidros de penicilina. Estas amostras tiveram o $\mathrm{pH}$ ajustado entre 6,8 e 7,2, foram mantidas sob refrigeração e levadas à Companhia Pernambucana de Saneamento - COMPESA, a fim de serem submetidas à sonicação (processo de rompimento das membranas celulares para fragilização das possíveis células de cianobactérias, e consequente liberação da toxina) no desruptor de células ultrasônico (modelo MA-103, Marconi). Em seguida, as amostras foram filtradas em filtros de fibra de vidro de $0,45 \mu \mathrm{m}$ e estocadas a $-20^{\circ} \mathrm{C}$ até o dia da análise de microcistina total pelo método ELISA ${ }^{24}$ através do kit de placa para extração de microcistinas da marca Envirologix ${ }^{\circ}$ (Portland, EUA) com limite de quantificação de $0,175 \mu \mathrm{g} / \mathrm{L}$ e limite de detecção de 0,147 $\mu \mathrm{g} / \mathrm{L}$.

Os resultados obtidos foram analisados espectrofotometricamente a $450 \mathrm{~nm}$, com o auxílio de leitor de ELISA STAT-FAX 2100 (Awareness Technology INC).

Com base nos resultados obtidos para os controles positivos, com o auxílio de um software de análise de dados, foi construída uma curva de calibração. Baseado nesta curva e nos valores obtidos por espectrofotometria para cada amostra foi possível determinar a concentração de microcistina nas amostras.

\section{Preparo das amostras para o CLAE}

Amostras de $500 \mathrm{~mL}$ coletadas no reservatório de Mundaú foram levadas para a Universidade Federal Rural de Pernambuco, na Unidade Acadêmica de Garanhuns, a fim de serem liofilizadas, para concentrar a toxina e extrair a microcistina total.

Depois de liofilizadas, as amostras foram submetidas a um processo para extração da microcistina total que consiste na adição de $20 \mathrm{~mL}$ de metanol $100 \%$ contendo $0,1 \%$ de ácido trifluoracético (TFA). O material foi transferido para um béquer de vidro de $100 \mathrm{~mL}$ e deixado por uma hora no banho de ultrasom a $40 \mathrm{kHz}$ (modelo Q335D, Quimis) para que houvesse o rompimento da membrana celular e a toxina fosse extraída. Em seguida, a amostra foi centrifugada por 10 minutos a $591 \mathrm{~g}$ e o sobrenadante guardado. Este mesmo procedimento foi realizado três vezes seguidas. Os sobrenadantes das três extrações, foram colocados em um único béquer, homogeneizado, transferido para um balão de fundo chato com tampa esmerilhada e secado em rotavapor (modelo 803, Fisatom) a $50{ }^{\circ} \mathrm{C}$, a $60 \mathrm{rpm}$ até que o metanol evaporasse completamente. Em seguida, o material foi ressuspendido em $10 \mathrm{~mL}$ de metanol a $20 \%{ }^{25}$.

A extração em fase sólida foi feita utilizandose o extrator Manifold (modelo Varian, Agilent Technologies). As amostras foram secadas em rotavapor nas mesmas condições anteriores, ressuspendidas em $1 \mathrm{~mL}$ de metanol grau CLAE e filtradas em filtros Millex LCR com membrana de PTFE modificada de $0,45 \mu \mathrm{m}$ e $13 \mathrm{~mm}$, para então serem injetadas no cromatógrafo. Os extratos concentrados ficaram conservados em freezer a $-20{ }^{\circ} \mathrm{C}$ até o momento da análise cromatográfica ${ }^{25}$.

A concentração da toxina em cada amostra foi determinada utilizando padrão de microcistina-LR puro na concentração de $0,5 \mathrm{mg}$ (Alexis Corporation-Lausen, Switzerland). A toxina foi identificada comparando o tempo de retenção do pico extraído com o do padrão de microcistina-LR.

As determinações analíticas de microcistina foram feitas no Laboratório de Processos e Produtos Biotecnológicos da Universidade de Pernambuco empregando um cromatógrafo Agilent série 1200 equipado com um detector de arranjo de diodos. Foi utilizada uma coluna Phenomenex C18 Synergi Fusion (50 $\mathrm{mm} \times 2,0 \mathrm{~mm} \times 2,5 \mu \mathrm{m}$ ) mantida a uma temperatura de $60^{\circ} \mathrm{C}$. A fase móvel foi constituída por água ultrapura Milli-Q e acetonitrila grau CLAE ambos contendo 0,1 $\%$ de TFA. A acetonitrila foi previamente filtrada em membrana de polipropileno hidrofílica de $0,22 \mu \mathrm{m}$. A separação cromatográfica foi feita com uma taxa de fluxo 
de $1 \mathrm{~mL} /$ minuto, usando um gradiente de eluição que começou com $20 \%$ de acetonitrila, aumentando até 70 $\%$ ao fim de 4 minutos, seguido de uma diminuição até os $20 \%$ aos 5 minutos e se mantendo constante até o final dos 7 minutos. O volume injetado foi de $20 \mu \mathrm{L}$. As microcistinas foram detectadas devido a sua capacidade de absorvância aos $238 \mathrm{~nm}^{26}$. As concentrações foram determinadas a partir da comparação do tempo de retenção da amostra com o tempo de retenção do padrão de microcistina-LR previamente injetado.

\section{RESULTADOS E DISCUSSÃO}

A eutrofização em lagos e reservatórios é um problema que ocorre em todo o mundo, tendo como alguns efeitos adversos, as florações de cianobactérias ${ }^{27}$. No reservatório de Mundaú, tais circunstâncias foram observadas com a ocorrência de florações durante todo o período de estudo. No ponto de captação do reservatório de Mundaú foram realizadas 15 amostragens em duplicata entre os meses de janeiro de 2011 a abril de 2012, sendo detectada a presença de cianobactérias produtoras de toxinas para todas as datas com quantidades acima de 20.000 cel. $\mathrm{mL}^{-1}$, condição suficiente para que seja recomendada a análise de microcistinas segundo preconizado pela Portaria $n^{\circ} 2914 / 11$ do Ministério da $S_{a u ́ d e}{ }^{13}$. O critério utilizado para avaliar os valores máximos permitidos (VMP) para as densidades celulares é o preconizado pela RDC 357/2005, CONAMA ${ }^{28}$.

A primeira etapa da análise foi a amostragem, cuja qualidade é determinante para um resultado preciso e exato ${ }^{29}$. Microcistinas podem sofrer degradação caso as amostras não sejam devidamente armazenadas e transportadas, podendo levar a graves erros na determinação da concentração na amostra original. Essa degradação pode ser evitada pela refrigeração das amostras a uma temperatura igual ou inferior a $4{ }^{\circ} \mathrm{C}$ ou pela adição de algum conservante ou agente biocida e, segundo Utkilen e Gjolme ${ }^{30}$, o metanol pode retardar esta degradação ${ }^{30}$. Portanto, para evitar que houvesse degradação das amostras, o processamento das amostras para o ELISA se deu no mesmo dia em que foram coletadas, uma vez que o solvente final é a própria água. Em seguida, as amostras foram estocadas a $-20^{\circ} \mathrm{C}$ até o dia da análise. Para a CLAE, as amostras foram congeladas para serem liofilizadas e como o processo de extração é muito longo, este só era interrompido nas etapas em que havia adição de metanol para evitar que houvesse degradação.

Outro fator importante para ser observado é o ajuste do $\mathrm{pH}$ da amostra entre 6,8 e 7,2. O objetivo deste ajuste é evitar que as toxinas não sejam co-extraídas durante a extração em fase sólida. Para este ajuste foi utilizado o ácido clorídrico p.a.

Com relação ao método imunológico, para cada uma das amostras analisadas via CLAE, também foi realizada a quantificação por ELISA. A equação de regressão linear e o coeficiente de determinação $\left(\mathrm{R}^{2}\right)$ foram calculados a fim de obter a curva analítica para avaliar a eficácia do teste e também quantificar as microcistinas presentes nas amostras de água. Estes resultados são mostrados na Figura 1 e estão diretamente relacionados com a sensibilidade e a linearidade do método.

A curva analítica obtida para a microcistina foi linear, apresentando coeficiente de determinação superior a 0,99. A Agência Nacional de Vigilância Sanitária recomenda um coeficiente (R) igual ou superior a $0,99^{31}$ e o Instituto Nacional de Metrologia, Normalização e Qualidade Industrial um valor acima de $0,90^{32}$. Este coeficiente de determinação foi satisfatório, o que demonstra que a resposta do método foi linear nos intervalos de concentração empregados neste estudo.

A precisão do teste foi avaliada através dos coeficientes de variação dos resultados obtidos ao nível de repetibilidade, sendo, portanto, feita em curto intervalo de tempo. Apesar dos ensaios terem sido feitos apenas em duplicata, foi observado que os coeficientes de variação variaram de 0,193 a 13,127 \% (Tabela 1) entre amostras e controles. Para o estudo da precisão, sabe-se que os intervalos dos coeficientes de variação são considerados adequados até $\pm 20 \%$ dependendo da complexidade da amostra. Os resultados obtidos neste estudo foram considerados precisos e dentro da faixa aceitável. Porém, para aumentar a precisão, faz-se necessário aumentar o número de réplicas.

Da equação da reta pode-se estimar a sensibilidade da técnica, definida como dy/dx, que apresentou valor de 18,22 , sendo, portanto, considerada satisfatória.

A Portaria 2.914/2011 $1^{13}$ do Ministério da Saúde, estabelece os procedimentos e responsabilidades relativas ao controle e vigilância da qualidade da água para consumo humano e seu padrão de potabilidade. A portaria exige que os responsáveis pelo controle da qualidade da água de sistemas de abastecimento supridos por mananciais superficiais monitorem as cianobactérias no ponto de captação de água 
Tabela 1. Resultado da quantificação das amostras pelo método ELISA

\begin{tabular}{|c|c|c|c|c|c|}
\hline $\begin{array}{l}\text { Amostras } \\
\text { Coletadas }\end{array}$ & $\begin{array}{c}\text { Média das } \\
\text { densidades ópticas }\end{array}$ & \% Desvio Padrão & $\begin{array}{c}\% \\
\text { Coeficiente de } \\
\text { Variação }\end{array}$ & $\begin{array}{c}\% \\
\text { Bo }\end{array}$ & $\begin{array}{c}\text { Conc. Microcistina } \\
(\mathbf{p p b})\end{array}$ \\
\hline $\mathrm{CN}$ & 1,463 & 0,003 & 0,193 & 100 & NA \\
\hline CP 0,16 ppb & 1,262 & 0,008 & 0,672 & 86 & NA \\
\hline CP 0,60 ppb & 0,950 & 0,054 & 5,734 & 65 & NA \\
\hline CP 2,5 ppb & 0,520 & 0,033 & 6,255 & 36 & NA \\
\hline Amostra 1 & 0,818 & 0,051 & 6,224 & 56 & 0,88 \\
\hline Amostra 2 & 0,687 & 0,037 & 5,459 & 47 & 1,45 \\
\hline Amostra 3 & 0,694 & 0,074 & 10,706 & 47 & 1,41 \\
\hline Amostra 4 & 0,707 & 0,057 & 8,107 & 48 & 1,34 \\
\hline Amostra 5 & 0,555 & 0,044 & 7,899 & 38 & 2,37 \\
\hline Amostra 6 & 0,464 & 0,032 & 6,865 & 32 & 3,34 \\
\hline Amostra 7 & 0,492 & 0,006 & 1,150 & 34 & 3,00 \\
\hline Amostra 8 & 0,584 & 0,040 & 6,907 & 40 & 2,13 \\
\hline Amostra 9 & 0,697 & 0,033 & 4,667 & 48 & 1,39 \\
\hline Amostra 10 & 0,556 & 0,055 & 9,920 & 38 & 2,36 \\
\hline Amostra 11 & 0,576 & 0,066 & 11,427 & 39 & 2,20 \\
\hline Amostra 12 & 0,536 & 0,042 & 7,915 & 37 & 2,55 \\
\hline Amostra 13 & 0,610 & 0,016 & 2,668 & 42 & 1,93 \\
\hline Amostra 14 & 0,523 & 0,069 & 13,127 & 36 & 2,68 \\
\hline Amostra 15 & 0,640 & 0,044 & 6,850 & 44 & 1,72 \\
\hline
\end{tabular}

$\mathrm{CN}$ (controle negativo); CP (controle positivo); NA (não avaliado)

mensalmente, quando o número de células de cianobactérias não exceder 10.000 células. $\mathrm{mL}^{-1}$, e semanalmente, quando o número de células de cianobactérias exceder esse valor. Também exige que sempre que o número de cianobactérias no ponto de captação exceder 20.000 células. $\mathrm{mL}^{-1}$ seja realizada a análise semanal das cianotoxinas. Esta Portaria determina no $5^{\circ}$ parágrafo do Artigo 40 que "quando as concentrações de cianotoxinas no manancial forem menores que seus respectivos VPMs para água tratada será dispensada a análise de cianotoxina na saída do tratamento de que trata o Anexo XII a essa
Portaria”. Com exceção da amostra 1, em todas as demais foi detectada a presença de microcistina no ponto de captação do manancial, antes do tratamento, acima do valor máximo permitido, indicando a importância desta análise em águas de abastecimento público. As análises das amostras sedimentadas nas cubetas de Utermöhl, para contagem de cianobactérias apresentaram valores superiores a 1.000.000 cel. $\mathrm{mL}^{-1}$, constituindo um grande indicativo da presença de cianotoxinas neste manancial.

As análises confirmaram a presença da toxina na maioria das amostras e a maior concentração da toxina 
determinada foi de $3,34 \mu \mathrm{g} . \mathrm{L}^{-1}$ de microcistina-LR, três vezes maior do que o limite máximo permitido pela legislação.

Para a CLAE, a fase de extração das microcistinas é determinante para a análise. Logo, algumas considerações iniciais com relação a esta etapa são necessárias.

Sabe-se que a microcistina-LR é um composto hidrofóbico, e sua concentração em águas superficiais é encontrada em níveis de partes por bilhão $\left(\mu \mathrm{g} . \mathrm{L}^{-1}\right)$ ou ainda menores e, como a determinação direta não pode ser viável devido à sensibilidade inadequada dos métodos de detecção utilizados para os níveis de concentração usualmente encontrados, uma etapa de concentração é normalmente necessária. Essa etapa, além de concentrar os analitos presentes nas amostras, também serve como uma etapa de limpeza ajudando a diminuir a interferência de substâncias que possam ser co-extraídas com os analitos de interesse, podendo assim interferir nas análises, tanto na separação cromatográfica, como na supressão do sinal da toxina ${ }^{33}$. Portanto, foi realizada uma extração em fase sólida para concentrar a toxina.

Estudos mostram a importância da escolha dos cartuchos. Trabalhos realizados por Wang et $\mathrm{al}^{34} \mathrm{e}$ Mekebri et $\mathrm{al}^{35}$ a fim de avaliar a eficiência de extração de alguns tipos de cartucho mostraram que aqueles que são compostos por uma mistura de C18 e sílica são menos eficientes na recuperação do analito de interesse, quando comparados com os compostos apenas de C18, possuindo uma relação custo-benefício bem melhor. O cartucho de extração utilizado neste trabalho foi um C18 com sílica que é bastante utilizado para esta finalidade, o que pode explicar o fato dos resultados das amostras na CLAE terem sido menos expressivos que os do ELISA.

Rivasseau et $\mathrm{a}^{36}$ avaliaram o efeito de lavagens com diferentes concentrações de metanol em água e observaram que a melhor recuperação se deu utilizando o metanol $20 \%$ pela maior eficiência na remoção de interferentes da amostra. Esta mesma concentração foi utilizada para a limpeza dos cartuchos durante a extração de fase sólida das amostras analisadas neste estudo.

Rivasseau et $\mathrm{al}^{36}$ também fizeram um estudo em cartucho C18 para avaliar três diferentes solventes em relação a recuperação da toxina retida no cartucho e observaram que o metanol acidificado com $0,1 \%$ de TFA foi o que obteve melhor resultado. Para tanto, todas as amostras analisadas no cromatógrafo foram ressuspendidas em metanol acidificado.

Com relação aos índices de recuperação das amostras, em se tratando da quantidade de amostra a ser filtrada e concentrada, Bogialli et $\mathrm{al}^{37}$ fizeram um estudo com três diferentes volumes de amostras (500 $\mathrm{mL}, 1 \mathrm{~L}$ e $2 \mathrm{~L}$ ) e concluíram que a amostra com menor volume apresentava um maior índice de recuperação, possivelmente devido a menor concentração de possíveis interferentes na etapa de extração. Logo, o volume da amostra escolhido para ser filtrado neste estudo foi de $500 \mathrm{~mL}$.

A etapa de eluição do cartucho, ou seja, a recuperação do analito depende do tipo de composto a ser analisado e do tipo de cartucho. Em cartuchos que retêm fortemente compostos hidrofóbicos na presença de água, como os do tipo C18, na presença de solventes orgânicos essa força de interação é bem menor, por isso, solventes orgânicos puros, como acetonitrila e metanol, são geralmente empregados. Portanto, estes foram os solventes de escolha para reconstituição das amostras durante a análise ${ }^{37}$.

Para o método cromatográfico, após terem sido determinadas as condições ideais para a análise de microcistina utilizando uma coluna de ultra eficiência, injetou-se o padrão de microcistina-LR. O comprimento de onda correspondente à absorção máxima do analito em estudo foi de $238 \mathrm{~nm}$. Análises anteriores a este estudo realizadas por nosso grupo utilizando cepas produtoras de microcistinas e também padrão de microcistinaLR da marca Alexis ${ }^{\oplus}$ mostraram que o pico referente à microcistina para coluna Synergi ${ }^{\circledR}$ apresenta um tempo de retenção de aproximadamente 2,9 minutos.

Neste estudo, foi possível detectar a presença de microcistina em $100 \%$ das amostras analisadas, uma vez que no mesmo tempo de retenção do padrão utilizado (aproximadamente aos 2,9 minutos) surgiram em todas as amostras picos quase que idênticos (Figura 2) sendo possível inferir que há presença de microcistina nas amostras analisadas (dados não mostrados).

$\mathrm{Na}$ análise cromatográfica não foi possível à quantificação das microcistinas presente nas amostras, sendo feita apenas uma análise qualitativa (presença ou ausência). Vale ressaltar que isto ocorreu possivelmente devido ao uso de um padrão de microcistina que já havia sido utilizado anteriormente em outras análises e não se tinha a concentração exata do mesmo. Sendo assim, quando o padrão foi diluído para construção da curva de calibração não apareceu nenhum pico no cromatograma, 
apenas foi identificado o pico referente à microcistina quando foi injetado o padrão na concentração inicial. Logo, não foi possível fazer uma curva de calibração e, por conseguinte, não foi possível quantificar as amostras.

Nesse sentido, faz-se necessária a validação de ambos os métodos utilizando um material de referência certificado contendo concentrações conhecidas de microcistinas, a fim de obter resultados confiáveis para a implementação final das referidas metodologias.

\section{CONCLUSÃO}

O estudo mostrou a importância da análise de microcistinas na água de abastecimento público, pois assim como Mundaú, vários mananciais de Pernambuco apresentam florações de cianobactérias. Além disso, permitiu a implementação da análise de microcistina pelos métodos ELISA e CLAE no LACEN-PE, tendo em vista que os resultados das análises indicaram a presença da toxina. Também mostrou sua importância como método complementar à contagem das cianobactérias, fornecendo subsídios às ações preventivas de vigilância à saúde.

Espera-se que este estudo sirva de base para avaliar o uso das metodologias e, dependendo da amostra de água a ser analisada, escolher a metodologia mais apropriada. A ideia central seria utilizar o método ELISA para a água tratada, indústria de injetáveis e clínicas de hemodiálise e a CLAE para a água bruta, uma vez que o ELISA é mais sensível. Isso reduziria os custos das análises para o LACEN-PE, pois o kit empregado no ELISA tem pouco custo-benefício por ser muito caro e analisar um pequeno número de amostras. Já a CLAE é um pouco menos sensível, mas muito específica e é recomendada pela Organização Mundial de Saúde como um dos métodos mais seguros.

Cabe ressaltar que, para a liberação dos resultados dessas análises para a Vigilância Sanitária, os procedimentos analíticos devem ser submetidos à validação estatística, com o objetivo de conhecer suas limitações e confiabilidade dos resultados obtidos para aplicação correta dos métodos de acordo com as amostras que se deseja analisar. Apesar destes métodos já serem validados para a análise de microcistinas em água ${ }^{25,26}$, como se trata de uma implementação, faz-se necessário uma revalidação antes de serem utilizados como análises de rotina para o monitoramento desta toxina.

\section{AGRADECIMENTOS}

À química Tânia Maria de Oliveira da Companhia de Pernambucana de Abastecimento (COMPESA) por ceder o desruptor de células para a sonicação das amostras, ao Prof. Dr. Renato José Reis Molica da Universidade Federal Rural de Pernambuco na Unidade Acadêmica de Garanhuns por ceder o liofilizador para extração das toxinas das amostras, às Vigilâncias Ambiental e Sanitária pelo suporte durante as coletas no reservatório e ao Laboratório Central de Saúde Pública (LACEN-PE) por ceder a estrutura, equipamentos e reagentes necessários à realização deste trabalho.

\section{REFERÊNCIAS}

1. Libânio M. Fundamentos de qualidade e tratamento de água. Campinas, São Paulo: Átomo; 2008.

2. Sanches SM, Vieira EM, Prado EL, Beneti F, Takayanagui AMM. Estudo da presença da toxina microcistina - LR em água utilizada em clínica de hemodiálise e validação de um método analítico. Ecl Quim.2007;32(4):43-8.

3. Cerione EM, Cavagioni MG, Breir TB, Barrella W, Almeida VP. Levantamento de espécies de algas planctônicas e análise da água do lago do Zoológico Quinzinho de Barros, Sorocaba (SP). REB.2008;1(2):18-27.

4. Codd GA, Azevedo SMFO, Bagchi SN, Burch MD, Carmichael WW, Harding WR, Utiklen HC. Cyanonet - A global network for cyanobacterial bloom and toxin risk management. Initial situation assessment and recommendations. IHP-VI Technical Document in Hidrology, n. 76. Unesco, Paris, Working Series SC 2005/WS/55, 2005.

5. Oberholster PJ, Myburghb JG, Govender D, Bengis R, Botha AM et al. Identification of toxigenic Microcystis strains after incidents of wild animal mortalities in the Kruger National Park, South Africa. Ecotoxicol Environm Saf.2009;72:1177-82.

6. Fernandes VO, Cavati B, Oliveira LB, Souza BDA. Ecologia de cianobactérias: fatores promotores e consequências das florações. Oecol Bras.2009;13(2):247-58.

7. Carneiro TG, Leite F. Cianobactérias e suas toxinas. Rev Analyt.2008; 32:36-41.

8. Abramsson-Zetterberg LU, Sundh R, Mattsson R. Cyanobacterial extracts and microcystin-LR are inactive in the micronucleus assay in vivo and in vitro. Mutat Res.2010;699(1-2):5-10.

9. Nybom SNK, Dziga D, Heikkilä J, Kull T, Salminen SJ, Meriluoto JAO. Characterization of mycrocistin-LR removal process in the presence of probiotic bacteria. Toxicon.2012;59(1):171-81.

10. Carmichael WW. The toxins of cyanobacteria. Sci Am.1994;270:78-86. 
11. Falconer IR. Tumor promotion and liver injury caused by oral consumption of cyanobacteria. Environm Toxicol.1991;6:177-84.

12. Meng G, Sun Y, Fu W, Guo Z, Xu L. Microcystin-LR induces cytoskeleton system reorganization through hyperphosphorylation of tau and HSP27 via PP2A inhibition and subsequent activation of the p38 MAPK signaling pathway in neuroendocrine (PC12) cells. Toxicology.2011;290:218-29.

13. Brasil. Ministério da Saúde. Portaria n ${ }^{\circ} 2914$, de 12 de dezembro de 2011. Dispõe sobre os procedimentos de controle e de vigilância da qualidade da água para consumo humano e seu padrão de potabilidade. Diário Oficial [da] República Federativa do Brasil. Brasília, DF, 14 dez. 2011. Seção 1. p. 39.

14. Chorus I, Bartram J. Toxic Cyanobacteria in Water: A Guide to their Public Health Consequences, Monitoring and Management. World Health Organization. London: E \& FN Spon;1999. 416pp.

15. Brasil. Ministério da Saúde. Portaria $n^{\circ} 518$, de 25 de março de 2004. Estabelece os procedimentos e responsabilidades relativos ao controle e vigilância da qualidade da água para consumo humano e seu padrão de potabilidade, e dá outras providências. Diário Oficial [da] República Federativa do Brasil. Brasília, DF, 26 mar. 2004.

16. Sant'Anna CL, Azevedo MTP, Werner VR, Dogo, CR, Rios FRC. Review of toxic species of Cyanobacteria in Brazil. Algol Stud.2008;126:215-65.

17. Molica RJR, Onodera H, Garcia C, Rivas M, Adrendo D, Nascimento $S$, et al. Toxins in the freshwater cyanobacterium Cylindrospermopsis raciborskii (Cyanophyceae) isolated from Tabocas reservoir in Caruaru, Brazil, including demonstration of a new saxitoxin analogue. Phycologia.2002; 41:606-11.

18. Azevedo SMFO. Toxic cyanobacteria and the Caruaru tragedy. IV Simpósio da Sociedade Brasileira de Toxicologia; 1996; p.84.

19. Jochimsen EM, Carmichael WW, An JS, Cardo DW, Cookson ST, Holmes CE, et al. Liver failure and death after exposure to microcystin toxins at a hemodialysis center in Brazil. N Engl J Med.1998;13(338):873-78.

20. Chellappa NT, ChellappaSL, ChellappaS. Harmful Phytoplankton Blooms and Fish Mortality in a eutrophicated reservoir of Northeast Brazil. Braz Arch Biol Technol.2008;51(4):833-41.

21. Agência Pernambucana de Águas e Clima. Rio Mundaú [Internet]. Recife [acesso em 20 dez.2012]. Disponível em: http:// www.apac.pe.gov.br/pagina.php?page_id=5\&subpage_id=19

22. Secretaria de Recursos Hídricos de Pernambuco (SRH). Plano Estadual de Recursos Hídricos do Estado de Pernambuco. Documento Síntese, Recife, 2000. 267pp.

23. UtermöhlH.Zurvervollkommer derquantitativen phytoplankton methodik. Mitt Int Ver. Theor Angew Limnol.1958;5:567-96.

24. Harada K, Kondo F, Lawton L. Laboratory Analysis of Cyanotoxins. In: Chorus I, Bartram J. Toxic Cyanobacteria in Water: A Guide to their Public Health Consequences, Monitoring and Management. World Health Organization. London: E \& FN Spon;1999. p.362-400.
25. Fastner J, Flieger I, Neumann U. Optimised extraction of microcystins from field samples - a comparison of different solvents and procedures. Water Res.1998;32:3177-81.

26. Lawton LA, Edwards C, Codd GA. Extraction and highperformance liquid chromatographic method for the determination of microcystins in raw and treated waters. Analyst.1994;119(7):1525-30.

27. Heo WM, Kim B. The effect of artificial destratification on phytoplankton in a reservoir. Hydrobiologia.2004;524:229-39.

28. Brasil. Resolução no 357, de 17 de março de 2005. Dispõe sobre a classificação dos corpos de água e diretrizes ambientais para o seu enquadramento bem como estabelece as condições e padrões de lançamento de efluentes, e dá outras providências. Diário Oficial [da] República Federativa do Brasil. Brasília, DF, 18 mar. 2005. Seção 1. p. 53.

29. Mozaz SR, Alda MJL, Barcelo D. Advantages and limitations of on-line solid phase extraction coupled to liquid chromatographymass spectrometry technologies versus biosensors for monitoring of emerging contaminants in water. J Chromatogr A.2007;1152:97-115.

30. Utkilen H, Gjolme N. Iron-Stimulated Toxin Production in Microcystis aeruginosa. Appl Environ Microbiol.1995;61:797-800.

31. Agência Nacional de Vigilância Sanitária; ANVISA. Resolução n. 899, de 29 de maio de 2003. Guia para Validação de Métodos Analíticos e Bioanalíticos. Diário Oficial [da] República Federativa do Brasil. Brasília, DF, 2 jul. 2003.

32. Instituto Nacional de Metrologia, Normalização e Qualidade Industrial. DOQ-CGCRE-008: Orientações sobre validação de métodos de ensaios químicos. Rio de Janeiro (RJ): INMETRO; 2011. Revisão 4. 20 p.

33. Msagati TAM, Siame BA, Shushu DD. Evaluation of methods for the isolation, detection and quantification of cyanobacterial hepatotoxins. Aquat Toxicol.2006;78:382-97.

34. Wang D, Weston DP, Lydy MJ. Method development for the analysis of organophosphate and pyrethroid insecticides at low parts per trillion levels in water. Talanta.2009;78:345-51.

35. Mekebri A, Blondina GJ, Crane DB. Method validation of microcystins in water and tissue by enhanced liquid chromatography tandem mass spectrometry. J Chromatogr A.2009;1216:3147-55.

36. Rivasseau C, Martins S, Hennion MC. Determination of some physicochemical parameters of microcystins (cyanobacterial toxins) and trace level analysis in environmental samples using liquid chromatography. J Chromatogr A.1998;799:155-69.

37. Bogialli S, Bruno M, Curini R, Di Corcia A, Fanali C, Laganà A. Monitoring algal toxins in lake water by liquid chromatography tandem mass spectrometry. Environ Sci Technol.2006;40:2917-23. 